\title{
Drying microclimates threaten persistence of natural and translocated populations of threatened frogs
}

\author{
Emily P. Hoffmann ${ }^{1}$ (D) Kim Williams $^{2} \cdot$ Matthew R. Hipsey $^{3}$ (D) \\ Nicola J. Mitchell ${ }^{1}$ ii
}

Received: 20 July 2020 / Revised: 6 October 2020 / Accepted: 7 October 2020 /

Published online: 27 October 2020

(C) The Author(s) 2020

\begin{abstract}
Defining species habitat requirements is essential for effective conservation management through revealing agents of population decline and identifying critical habitat for conservation actions, such as translocations. Here we studied the habitat-associations of two threatened terrestrial-breeding frog species from southwestern Australia, Geocrinia alba and Geocrinia vitellina, to investigate if fine-scale habitat variables explain why populations occur in discrete patches, why G. alba is declining, and why translocation attempts have had mixed outcomes. We compared habitat variables at sites where the species are present, to variables at immediately adjacent sites where frogs are absent, and at sites where G. alba is locally extinct. Dry season soil moisture was the most important predictor of frog abundance for both species, and explained why G. alba had become extinct from some areas. Sites where $G$. alba were present were also positively associated with moss cover, and negatively with bare ground and soil conductivity. Modelling frog abundance based exclusively on dry season soil moisture predicted recent translocation successes with high accuracy. Hence, considering dry season soil moisture when selecting future translocation sites should increase the probability of population establishment. We propose that a regional drying trend is the most likely cause for $G$. alba declines and that both species are at risk of further habitat and range contraction due to further projected regional declines in rainfall and groundwater levels. More broadly, our study highlights that conservation areas in drying climates may not provide adequate protection and may require interventions to preserve critical habitat.
\end{abstract}

Keywords Amphibian conservation · Climate $\cdot$ Habitat $\cdot$ Population decline $\cdot$ Soil moisture - Geocrinia

Communicated by Dirk Sven Schmeller.

Electronic supplementary material The online version of this article (https://doi.org/10.1007/s10531-02002064-9) contains supplementary material, which is available to authorized users.

Emily P. Hoffmann

emily.hoffmann@research.uwa.edu.au

Extended author information available on the last page of the article 


\section{Introduction}

Defining the environmental factors that determine species distributions is invaluable for effective species conservation and management. Population declines due to environmental change are prevalent worldwide (Pereira et al. 2012) and so understanding the environmental limits of species is critical for predicting future biodiversity. Species-habitat associations can be used to identify threatening processes and enable management actions that may halt or reverse declines, and ultimately prevent species extinctions (Caughley 1994). For example, defining species' habitat requirements can improve recovery actions, such as conservation translocations (Morris et al. 2015; McCulloch and Norris 2001). A key challenge for recovering threatened species is identification of suitable reintroduction sites, and low habitat suitability or a lack of consideration of micro-habitat are prime reasons for translocation failure (Germano and Bishop 2009; Bennett et al. 2013). Yet despite potential benefits to conservation, the fine-scale habitat associations that determine a species occurrence are often unknown.

The availability of detailed information on environmental requirements is particularly important for amphibians. Over 40\% of amphibian species are threatened (IUCN Red List 2020), and the causes of declines and local extinctions are not universally known (Stuart et al. 2004). Being ecothermic vertebrates, the body temperature of amphibians is largely determined by their microenvironment, and their permeable skin and unshelled eggs make them especially sensitive to water loss and pollutants (Hillman et al. 2009). As a consequence, amphibians are highly sensitive to changes in habitat and are more vulnerable to changes in climate than other vertebrates (Blaustein et al. 2010; Walls et al. 2013; Rolland et al. 2018). Detailed knowledge of species-habitat associations can hence improve our understanding of how the amphibians may respond to future changes, such as hotter and/or drier climates, and can aid recovery actions such as translocations (Li et al. 2013).

White- and orange-bellied frogs (Geocrinia alba and Geocrinia vitellina; WardellJohnson and Roberts, 1989) are terrestrial-breeding species with highly restricted distributions in south-western Australia (Fig. 1). The species are allopatric with at least $6 \mathrm{~km}$ between their range edges and occur in naturally fragmented sub-populations clustered along drainage lines and headwater streams. Geocrinia alba is Critically Endangered, with over half the known populations going extinct in recent decades, and extant populations continuing to decline (TSSC 2019). Considerable habitat clearance and land-use change in the region has been attributed to earlier extinction events, but more recently populations are disappearing in areas within conservation reserves that are apparently undisturbed (Page et al. 2018). Geocrinia vitellina is known from a very small area $\left(<6 \mathrm{~km}^{2}\right)$ and is listed as Vulnerable, however populations have remained relatively stable over time and are all within a contiguous national park (Department of Parks and Wildlife 2015). The causes of the patchy distributions of both species are unclear, as is the reason why some $G$. alba populations are declining in areas with apparently intact habitat.

Conservation translocations of head-started juvenile Geocrinia began in the 2000's and aimed to increase the number of sub-populations, but have had varying outcomes (Department of Parks and Wildlife 2015). One translocation site for G. alba has become a large self-sustaining population, whilst few or no calling males have been detected at other sites in the years following translocation. Juvenile frogs were all released into suitable looking riparian habitats near existing populations during spring and involved the release of a comparable number of individuals. Why some translocations have been more 


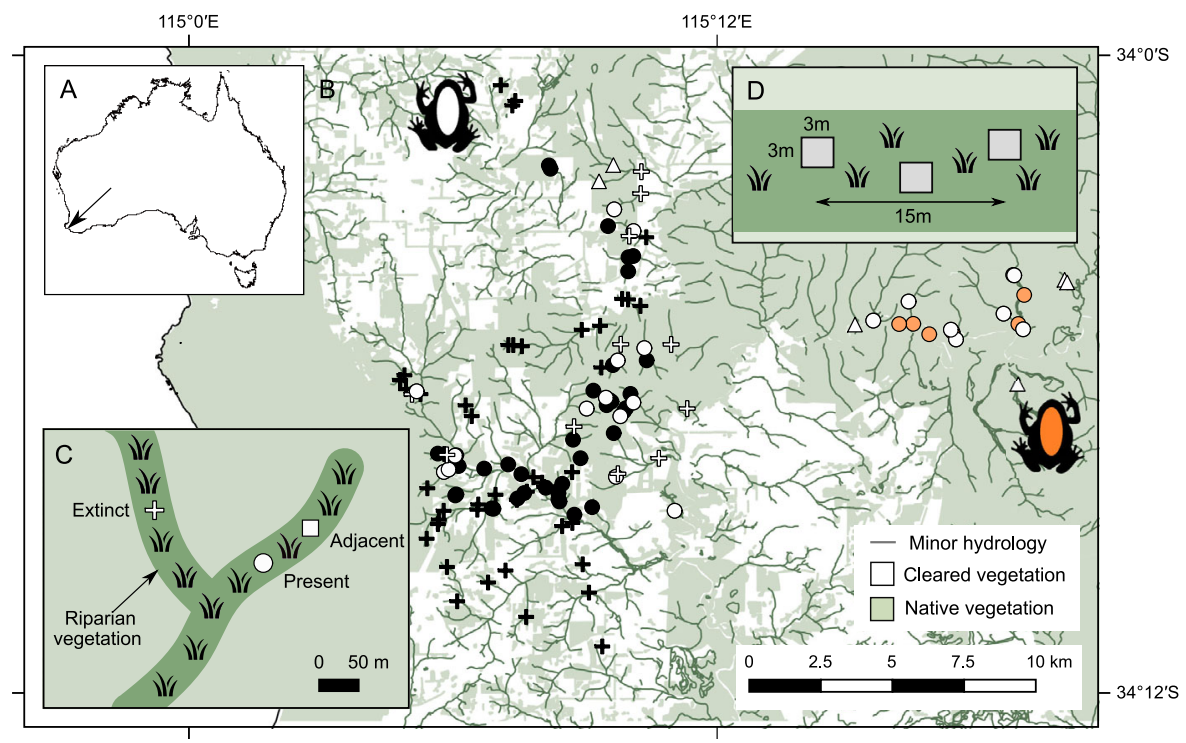

Fig. 1 Map of a the study area in southwest Western Australia b showing present (circles), extinct (crosses) and translocated (triangles) Geocrinia alba (black) and Geocrinia vitellina (orange) populations and sites sampled in this study (white symbols), c an example of the sampling design along drainage lines, showing sampled present site where frogs occur (circle), an immediately adjacent site (square) where frogs are absent, and a nearby extinct site (cross), and $\mathbf{d}$ an example of sampling quadrats at a site. Population locations and hydrology layers provided by Western Australian Department of Biodiversity Conservation and Attractions

successful than others has not been determined, and not knowing what makes a translocation site successful is currently constraining conservation management.

Patterns of population occurrence and persistence for both natural and translocated populations of $G$. alba and G. vitellina may relate to fine-scale differences in habitat. Both species exhibit extreme site philopatry, with $90 \%$ of individuals moving less than $20 \mathrm{~m}$ within and between years (Driscoll 1997). This low dispersal is evident from genetic studies that showed almost no gene flow between populations (Driscoll 1998a). As the species are specialised terrestrial breeders with entirely endotrophic (non-feeding) development (Mitchell 2001; Anstis 2010), their lifecycle is completed in and immediately adjacent to breeding sites. Breeding sites are vulnerable to extremes of flooding and desiccation, as eggs develop in moist soils but cannot be submerged (Wardell-Johnson and Roberts 1993). Hence if a habitat becomes unsuitable, these species have very limited ability to disperse to suitable habitat elsewhere.

Habitat floristics do not distinguish between persisting and extinct populations (Pauli 1999), but habitat structure may play a key role in where frogs occur. Both species live and breed under moss, litter and other vegetation (Driscoll 1998a; Conroy 2001) and therefore the availability of these features is likely important in determining their presence. Likewise, microclimate characteristics of nest sites and soil parameters, such as $\mathrm{pH}$ and conductivity, are other factors known to influence amphibian occurrence (Wyman 1988; Mitchell 2002a; Dodd 2010) that could also play a role in determining the distribution of G. alba and G. vitellina.

In this study our aim was to identify if variation in fine-scale habitat attributes could explain why populations of $G$. alba and G. vitellina occur in discrete patches along 
seemingly suitable riparian habitat, why $G$. alba is declining and has become absent from some sites whilst $G$. vitellina sites are more stable, and why translocation efforts for both species have had mixed outcomes. Based on current knowledge of the species, we explored four hypotheses to explain their persistence at sites. We hypothesised that frog occurrence, population declines, and translocation success are driven by differences in (1) site hydrology, (2) micro-climate, (3) habitat structure, and/or (4) soil characteristics. We predicted that sites where frogs persist would have higher year-round soil moisture, lower temperature extremes, more ground cover and soils with lower conductivity. We then use our findings on habitat associations based on occupied frog sites and successful translocation sites to provide recommendations for recognising critical habitat, and to identify key threats to the persistence of both species.

\section{Methods}

\section{Study area}

Geocrinia alba and Geocrinia vitellina occur along drainage areas and headwater streams in the Margaret River region in southwest Australia (Fig. 1). Drainage lines typically consist of dense riparian and rhizomatous vegetation with a shrub overstorey (e.g. Astartea fascicularis, Taxandria linearifolia, Homalospermum firmum), surrounded by jarrah (Eucalyptus marginata) and marri (Corymbia calophylla) forests, and are characterised by shallow water flows in winter (Wardell-Johnson and Roberts 1993). The region has a Mediterranean climate with a distinct wet period from May to October, and a dry period from November to April characterised by very little rainfall and high temperatures (Fig. 2). Cool wet winters and early spring coincide with frog breeding activity, and metamorphosis from terrestrial nest sites occurs from November to January.

\section{Site selection}

Geocrinia alba and G. vitellina habitats were sampled across four distinct site types, selected with reference to long-term acoustic monitoring records maintained by the Western Australian Department of Biodiversity, Conservation and Attractions (DBCA) (Fig. 1). The G. alba and G. vitellina monitoring program has been identified as an exemplary monitoring program for threatened frogs in Australia (Scheele and Gillespie 2018), with over 1760 surveys conducted across 150 sites since 1983. Frog populations are monitored annually or biannually, and monitoring includes point counts (where frog abundances are estimated from a single location) at all sites, as well as linear counts at selected sites, which involves counting all individuals and locating the first and last calling male in a breeding chorus along a drainage line. Translocation sites have census monitoring, where all calling individuals are located and recorded.

Present sites $(n=21)$ were locations where populations of $G$. alba or G. vitellina have consistently occurred, based on acoustic surveys conducted in spring. Present sites were selected at random from a list of all known present sites, where they were accessible (i.e. property access was permitted) and separated from another present site by at least $500 \mathrm{~m}$. Adjacent sites $(n=21)$ were unoccupied sites along potential riparian habitat for frogs, either $50 \mathrm{~m}$ directly upstream or downstream of a present population site.

While typical adult movements between years are less than $20 \mathrm{~m}$, the distance of $50 \mathrm{~m}$ is within the dispersal range of these species (Driscoll 1997), and so adjacent sites were 


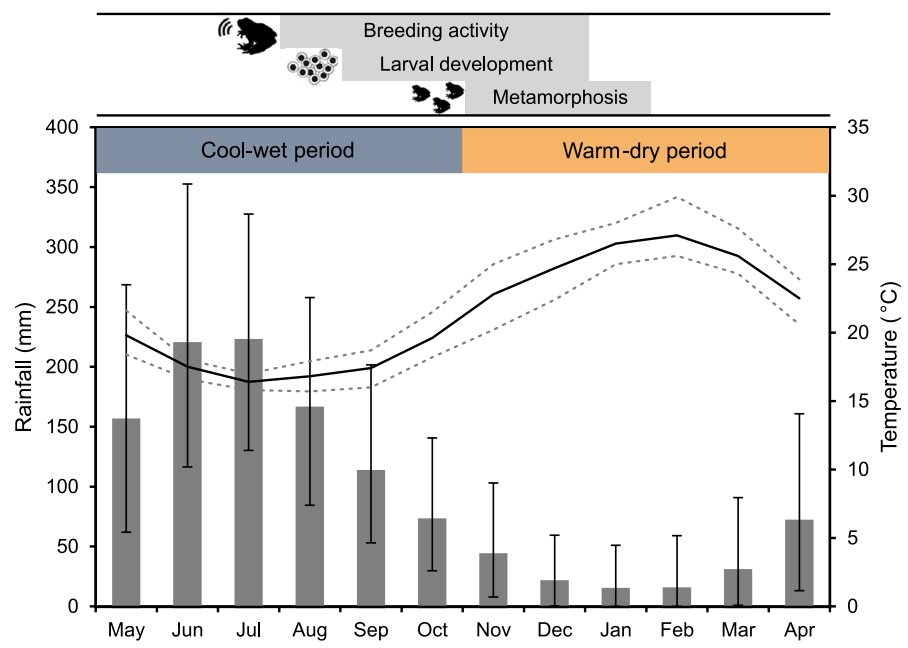

Fig. 2 Monthly averages (with $5 \%$ and $95 \%$ percentiles) of rainfall (vertical bars) and temperature (solid line) for the Margaret River region, showing distinct cool-wet winter and warm-dry summer periods. The relative timing of breeding activity (calling), larval development and metamorphosis of $G$. alba and $G$. vitellina (based on Conroy 2001; Anstis 2010) are shown by horizontal bars. Climate data are from weather stations at Witchcliffe (temperature from 1999 to 2018) and Forest Grove (rainfall from 1925 to 2018), located approximately 5 and $3 \mathrm{kms}$ from the study area (Bureau of Meteorology 2019)

potentially available to frogs, but could be confirmed as unoccupied due to their proximity to present sites that are routinely surveyed. Upstream or downstream sites were chosen at random (by the flip of a coin), unless only one direction fitted our selection criteria (i.e. there was only unoccupied habitat in one direction). Extinct sites $(n=11)$ were nearby sites where the species had occurred in the past but was not recorded by the DBCA for at least three years prior. Translocation sites $(n=6)$ were sites where head-started juvenile frogs (ranging from 68 to 145 individuals) had been introduced between 2010 and 2017 in locations where they had not been recorded previously (Table S1).

\section{Estimates of frog abundance}

We estimated frog abundance from acoustic monitoring data collected by DBCA staff during September-November, when the majority (76-96\%) of calling males in a population can be reliably detected (Driscoll 1998b). Frog call surveys were conducted after dusk by experienced DBCA staff, when the maximum number of males' call (Driscoll 1998b). The number of calling males was estimated over a 10-min period, and was considered to be a proxy for frog abundance that reflected relative differences in population size across sites. The number of males calling at a site was allocated to one of six categories $(0,1-4,5-10,11-20,21-50,>50)$, and the minimum value in each category was used as the estimate of male abundance for each site. This was the most conservative approach and was more informative than presence-absence data as it distinguished sites with only a few calling males from sites that supported much larger choruses. At translocation sites, frog abundance was estimated using a similar call survey technique but a censusing approach was employed, where the exact number of calling males were identified by marking their positions. 


\section{Habitat characteristics}

Habitat surveys were conducted towards the end of the warm-dry period, from April 14 to May 2 2018, following pilot surveys to determine the number of quadrats and samples required to quantify characteristics of a site. Habitat variables were sampled in three $3 \times 3 \mathrm{~m}$ quadrats at each site. The quadrats were established along a $15 \mathrm{~m}$ transect running along the edge of the riparian vegetation $(7.5 \mathrm{~m}$ apart), and then positioned at a random distance from the edge (into the riparian habitat) (Fig. 1). At each quadrat, fifteen habitat characteristics were measured relating to our four hypotheses; site hydrology, micro-climate, habitat structure, and soil characteristics (Table 1).

Soil moisture (volumetric water content, $\mathrm{m}^{3} \mathrm{~m}^{-3}$ ) was measured in the top $6 \mathrm{~cm}$ of soil using a hand-held moisture meter (ICT International, MP306). Five measurements were taken, one in each corner and one in the centre of the quadrat, and then were averaged per quadrat. Additional soil moisture measurements were taken at the end of the wet period (December 18-20 2018), but only in the central quadrat. The soil moisture meter was calibrated using soil samples from five sites that included all soil texture categories (see below). Soils were air-dried then wetted to create a range of moisture levels and the meter value was recorded and compared to the actual water content by oven drying the sample at $105{ }^{\circ} \mathrm{C}$ for $24 \mathrm{~h}$. Bulk density was determined with the core method using the same samples as were used for calibration of the meter.

Table 1 Fine-scale habitat variables used to investigate habitat associations of $G$. alba and G. vitellina populations in south-west Western Australia

\begin{tabular}{|c|c|c|}
\hline $\begin{array}{l}\text { Category } \\
\text { (Hypothesis) }\end{array}$ & Variable & Description \\
\hline \multirow[t]{2}{*}{ Hydrology } & SoilMoist_Dry $^{\mathrm{a}}$ & $\begin{array}{l}\text { Volumetric soil water content }\left(\mathrm{m}^{3} \mathrm{~m}^{-3}\right) \text { measured at the end of the } \\
\text { dry season, April } 2018\end{array}$ \\
\hline & SoilMoist_Wet & $\begin{array}{l}\text { Volumetric water content }\left(\mathrm{m}^{3} \mathrm{~m}^{-3}\right) \text { measured following the wet } \\
\text { season, December } 2018\end{array}$ \\
\hline \multirow[t]{2}{*}{ Micro-climate } & $\operatorname{TempMax}^{\mathrm{a}}$ & $\begin{array}{l}\text { Average daily soil temperature maximum }\left({ }^{\circ} \mathrm{C}\right) \text { in the hottest month, } \\
\text { February } 2019\end{array}$ \\
\hline & TempRange & $\begin{array}{l}\text { Average daily soil temperature range }\left({ }^{\circ} \mathrm{C}\right) \text { in the hottest month, } \\
\text { February } 2019\end{array}$ \\
\hline \multirow[t]{7}{*}{ Habitat structure } & CanopyCover $^{\mathrm{a}}$ & Average canopy cover $(\%)$ \\
\hline & BareGround $^{\mathrm{a}}$ & Average cover of bare ground $(\%)$ \\
\hline & $\operatorname{Moss}^{\mathrm{a}}$ & Average cover of moss $(\%)$ \\
\hline & SedgeCover & Average cover of sedges $(\%)$ \\
\hline & WoodyDebris & Average cover of coarse woody debris and logs $(\%)$ \\
\hline & LitterCover $^{\mathrm{a}}$ & Average cover of leaf litter $(\%)$ \\
\hline & LitterDepth & Average depth of the litter layer $(\mathrm{cm})$ \\
\hline \multirow[t]{4}{*}{ Soil properties } & Texture & $\begin{array}{l}\text { Soil texture classification based on five categories ranging from sand } \\
\text { (1) to clay (3) }\end{array}$ \\
\hline & OrganicCarbon & Soil organic carbon $(\%)$ \\
\hline & Conductivity $^{\mathrm{a}}$ & Soil electrical conductivity $\left(\mathrm{dS} \mathrm{m}^{-1}\right)$ \\
\hline & $\mathrm{pH}^{\mathrm{a}}$ & Soil pH $\left(\mathrm{CaCl}_{2}\right)$ \\
\hline
\end{tabular}

${ }^{\mathrm{a}}$ Variables used in the final generalised linear mixed-effect modelling 
One HOBO temperature logger (UA-001-08) was placed in each sites' central quadrat to obtain soil surface temperature data at hourly intervals. Loggers were placed in the most open patch of the quadrat, buried into the top layer of soil $(0-2 \mathrm{~cm})$ under any present surface covering (e.g. leaf litter) and secured with a survey pin. Canopy cover was estimated at each quadrat using a densiometer held approximately $1.2 \mathrm{~m}$ above ground level at each cardinal direction, and then averaged for each quadrat. Ground cover was estimated as the percent area of bare ground, moss, sedge, leaf litter, and coarse woody debris within the quadrat, and litter depth was measured at three random points using a ruler and then averaged for the quadrat. Soil samples were collected by scraping away any litter or moss covering and extracting three cores (of the top $10 \mathrm{~cm}$ ) from within each quadrat. Soil samples were bulked per site and analysed for texture (scale 1-3; Sand-Clay), organic carbon $(\%)$, conductivity $\left(\mathrm{dS} \mathrm{m}^{-1}\right)$, and $\mathrm{pH}\left(\mathrm{CaCl}_{2}\right)$ by an accredited soil laboratory (CSBP Soil and Plant Analysis Laboratory).

\section{Statistical analysis}

All statistical analyses were carried out in R (R Core Team 2019). To visualise differences in habitat characteristics across site types we used non-metric multidimensional scaling (NMDS). Plots were produced identifying site type (present, adjacent or extinct) using the 'vegan' package (Oksanen et al. 2019). Analysis of similarity (ANOSIM) was used to test whether there was a significant difference between habitat characteristics and site types.

To investigate which habitat features best explained frog abundance we used generalised linear mixed-effect models (GLMMs) with Poisson error distributions. We conducted three sets of analyses-first comparing present versus adjacent sites for G. alba and $G$. vitellina to investigate why frog populations occur in discrete patches, and then comparing present versus extinct sites for G. alba to examine possible mechanisms of G. alba decline. The response variable was the minimum estimated abundance of frogs at a site, and there were 15 potential explanatory habitat variables thought to be important in determining frog abundance. To avoid over parametrisation, we reduced correlated pairs of variables $(r>0.5)$ and retained one with the strongest effect on the model as a proxy (Booth et al. 1994). The reduced predictor variables set included dry season soil moisture, maximum temperature, canopy cover, bare ground, moss cover, litter cover, soil conductivity and soil $\mathrm{pH}$ (Table 1). Predictors were scaled and centered to have a mean of 0 and standard deviation of 1 (Harrison et al. 2018), allowing for comparison of effect sizes (Grueber et al. 2011). The areas containing paired sites (e.g. a present and nearby adjacent site) within the same catchment were included as a random effect. Models were fitted using the 'glmer' function in the package 'Ime4' (Bates et al. 2015).

All possible variable subsets were created and ranked based on Akaike information criterion adjusted for small sample size $\left(\mathrm{AIC}_{\mathrm{C}}\right)$. Model averaging was then conducted on the subset of models with high support $\left(\Delta \mathrm{AIC}_{\mathrm{C}} \leq 6\right.$ with the top ranked model, which includes the $95 \%$ confidence model set (Richards et al. 2011) using the 'modavg' function in the 'MuMIn' package (Barton 2019)). Rather than single best model methods, this allowed for model selection uncertainty, as inference was based on the entire candidate model set (Burnham and Anderson 2002). The relative importance of each variable across all models was determined by the sum of Akaike weights (Wi) (Burnham and Anderson 2002). Model diagnostics were investigated using the 'DHARMa' package (Hartig 2020) and indicated no overdispersion, outliers, or heteroscedasticity of the model residuals. We 
checked for collinearity among fixed effects by calculating variable inflation factors in all top models using 'vif' function in the 'car' package (Fox and Weisberg 2019).

Once dry season soil moisture was identified as one of the best explanatory variables of frog abundance (consistently significant for both species), we tested the accuracy of model predictions for translocation outcomes by comparing them with the actual outcomes of translocations (note that data from translocation sites were not used in the models described above). As the number of years since frogs were first introduced varied across translocation sites, we initially used abundance estimates from two years following the initial release of frogs, as this could be applied to all translocation sites. However, as the 2-year results did not differ from those using frog abundances from the year of the habitat surveys (2017), we used the more recent estimates from 2017. Generalised linear models of frog abundance were made for each species with dry season soil moisture as the explanatory variable, using the data from naturally occurring present and absent sites described above. Predictions of frog abundance were then made for existing translocation sites based on their dry season soil moisture, and the accuracy of predictions was investigated using Spearman's rank-order correlation. We also converted predicted and actual frog abundances into categories in order to construct a confusion matrix using the 'carot' package (Kuhn 2018). A cut-off value of $\geq 10$ frogs was used to define 'success' at a translocation site based on the criteria defined in the Geocrinia Recovery Plan (Department of Parks and Wildlife 2015).

\section{Results}

\section{Differences between G. alba and G. vitellina sites}

Analysis of microhabitat characteristics using NMDS showed there was a significant difference in the habitat characteristics of present, adjacent and extinct sites (Fig. 3; ANOSIM global $r=0.1802, p=0.001$ ). Present sites of both species had considerable overlap and were more similar to each other than their paired adjacent sites (50 m upstream or downstream) and extinct G. alba sites. Present sites for G. vitellina had some separation along the first ordination axis indicating higher soil moisture, moss and soil electrical conductivity than at the present sites for G. alba (Table S3). Adjacent and extinct sites were also separated mostly along the first ordination axis, signifying these sites had more bare ground, warmer temperatures and lower soil moisture and moss cover than present sites (Fig. 3).

\section{Habitat associations}

Frog abundance was posistively associated with dry season soil moisture for both G. alba and $G$. vitellina, and dry season soil moisture was present in all top models $\left(\Delta \mathrm{AIC}_{\mathrm{C}} \leq 6\right)$ across all three model sets (Table 2; Fig. 4). Dry season soil moisture also had the highest relative importance and effect size for models comparing G. alba present vs extinct sites and $G$. vitellina present vs adjacent sites, and was equally important in $G$. alba present vs adjacent sites (Table 2).

Geocrinia alba abundance (comparing present sites with extinct sites) was positively associated with moss cover and $\mathrm{pH}$ but the effect size was smaller. The confidence interval for $\mathrm{pH}$ was almost zero, specifying less evidence of an effect. Compared to adjacent sites, G. alba abundance was negatively associated with the area of bare ground and soil 
(a)

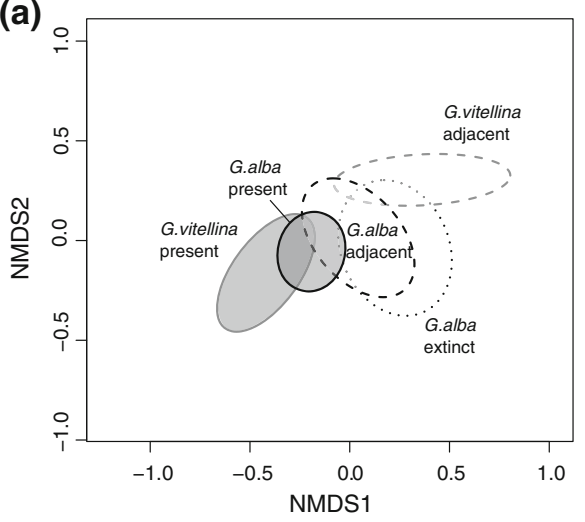

(b)

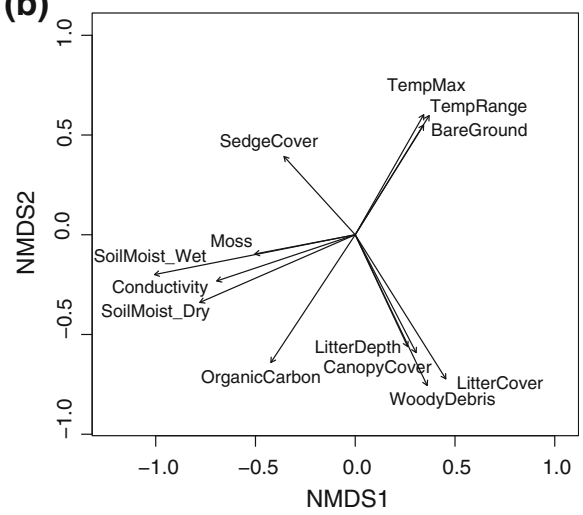

Fig. 3 Non-metric MDS ordination of site microhabitat characteristics showing a G. alba and G. vitellina present (shaded, solid line), adjacent (unshaded, dashed line) and extinct site types (unshaded, dotted line), and $\mathbf{b}$ vectors of environmental variables significantly related to the ordination $(p<0.01)$. Ellipses in a) show $95 \%$ confidence intervals. Stress $=0.17$

conductivity, which had the biggest effect sizes (Table 2; Fig. 5a, b). Geocrinia alba abundance was also positively associated with moss cover, similarly to present vs extinct sites (Fig. 5c). All four variables had equal relative importance (Table 2). For G. vitellina, several other variables were contained in the top models $\left(\Delta \mathrm{AIC}_{\mathrm{C}} \leq 6\right)$, but confidence intervals of the estimates included zero, indicating weak evidence for an effect (Table 2).

Dry season soil moisture, which was present in all top models for both species, was strongly negatively correlated with maximum soil temperature $\left(t_{57}=-6.45, \mathrm{p}<0.001\right.$, $\mathrm{r}=-0.65)$ and soil temperature range $\left(t_{57}=-8.23, \mathrm{p}<0.001, \mathrm{r}=-0.74\right)$ and was influenced by soil texture, with soils with higher clay content generally having higher soil moisture than sandier soils (Fig. S1).

\section{Predicting translocation outcomes}

Generalised linear models using dry season soil moisture as the sole predictor variable were good predictors of G. alba and G. vitellina abundances at translocation sites (Fig. 6). Predicted abundance was significantly correlated with actual abundances at translocation sites $\left(r_{s}=0.89, p=0.015\right)$. Using a cut-off value of $\geq 10$ calling males as a 'successful' translocation site, models of frog abundance exclusively based on dry season soil moisture correctly predicted translocation success or failure at with an overall accuracy of 0.83 (Table S5). Agreement between observed and predicted was substantial (Kappa $=0.67)$.

\section{Discussion}

Studies of species-habitat relationships often produce a myriad of complex associations, but here we were able to identify a single predictor that explained the majority of variation in frog abundance for both G. alba and G. vitellina and was validated using empirical data. Fine-scale habitat variables - particularly soil moisture during the warmer-drier monthsexplained not only the patchy distribution of each species, but also explained local extinctions of G. alba populations and translocation outcomes of G. alba and G. vitellina. 
Table 2 Averaged model coefficients from the top model set predicting abundance of $G$. alba (present vs extinct sites and present vs adjacent sites) and $G$. vitellina (present vs adjacent sites)

\begin{tabular}{lllll}
\hline Variable & Estimate & \multicolumn{2}{l}{ R5\% confidence interval } & Relative importance $\mathrm{n}$ models \\
\cline { 2 - 2 } & Lower $\quad$ Upper & \\
\hline
\end{tabular}

Geocrinia alba - present vs extinct sites

$\begin{array}{lrrrrr}\text { (Intercept) } & 0.8475 & -0.42 & 2.12 & & \mathbf{2 6} \\ \text { SoilMoist_Dry } & \mathbf{2 . 2 3 2 6} & \mathbf{1 . 0 3} & \mathbf{3 . 4 3} & \mathbf{1 . 0 0} & \mathbf{2 2} \\ \text { Moss } & \mathbf{1 . 1 7 8 2} & \mathbf{0 . 1 7} & \mathbf{2 . 1 9} & \mathbf{0 . 9 3} & \mathbf{1 8} \\ \text { pH } & \mathbf{1 . 0 1 3 9} & \mathbf{0 . 0 2} & \mathbf{2 . 0 1} & \mathbf{0 . 7 6} & 13 \\ \text { Conductivity } & -0.6349 & -1.31 & 0.04 & 0.48 & 12 \\ \text { CanopyCover } & 0.5146 & -0.14 & 1.17 & 0.39 & 5 \\ \text { TempMax } & -0.1974 & -1.60 & 1.20 & 0.13 & 5 \\ \text { BareGround } & -0.2788 & -1.04 & 0.48 & 0.11 & 5 \\ \text { LeafLitter } & 0.1326 & -0.75 & 1.02 & 0.09 & \end{array}$

Geocrinia alba-present vs adjacent sites

$\begin{array}{lrrrrr}\text { (Intercept) } & 0.68 & -0.01 & 1.36 & & \mathbf{9} \\ \text { Conductivity } & -\mathbf{1 . 7 8} & -\mathbf{2 . 4 4} & -\mathbf{1 . 1 2} & \mathbf{1 . 0 0} & \mathbf{9} \\ \text { BareGround } & -\mathbf{1 . 4 0} & -\mathbf{2 . 0 5} & -\mathbf{0 . 7 5} & \mathbf{1 . 0 0} & \mathbf{9} \\ \text { SoilMoist_Dry } & \mathbf{1 . 0 2} & \mathbf{0 . 4 5} & \mathbf{1 . 6 0} & \mathbf{1 . 0 0} & \mathbf{9} \\ \text { Moss } & \mathbf{0 . 6 1} & \mathbf{0 . 1 4} & \mathbf{1 . 0 8} & \mathbf{1 . 0 0} & 4 \\ \text { CanopyCover } & 0.42 & -0.30 & 1.14 & 0.29 & 3 \\ \text { LeafLitter } & 0.33 & -0.33 & 1.00 & 0.19 & 3 \\ \text { pH } & -0.14 & -0.70 & 0.42 & 0.12 & 2 \\ \text { TempMax } & -0.01 & -0.53 & 0.51 & 0.12 & \end{array}$

Geocrinia vitellina - present vs adjacent sites

$\begin{array}{lrrrrr}\text { (Intercept) } & -0.39 & -2.26 & 1.49 & & \\ \text { SoilMoist_Dry } & \mathbf{3 . 3 8} & \mathbf{1 . 5 8} & \mathbf{5 . 1 8} & \mathbf{1 . 0 0} & \mathbf{1 5} \\ \text { CanopyCover } & 1.19 & -0.52 & 2.90 & 0.31 & 6 \\ \text { BareGround } & -1.17 & -3.30 & 0.96 & 0.20 & 3 \\ \text { Moss } & 0.67 & -0.62 & 1.97 & 0.13 & 3 \\ \text { pH } & 0.47 & -0.47 & 1.42 & 0.13 & 2 \\ \text { LeafLitter } & -0.10 & -1.43 & 1.23 & 0.06 & 3 \\ \text { TempMax } & 0.41 & -1.14 & 1.97 & 0.09 & \end{array}$

Variables in bold indicate those with $95 \%$ confidence intervals that did not span zero. The relative importance of each variable (sum of Akaike weights) and the number of models in the top set containing the variable are also displayed

Geocrinia alba and G. vitellina appear to share the same environmental niche. The similarity in their habitat associations is not surprising as they are the most closely related species within the Geocrinia rosea complex, which includes four direct-developing frog species endemic to southwestern Australia (Read et al. 2001). Despite no overlap in their distributions, NMDS analysis revealed that present sites of each species had significant overlap in their habitat attributes and were more similar to each other than to riparian sites only $\sim 50 \mathrm{~m}$ from the edge of areas where frogs occur. This was particularly stark for $G$. 
Fig. 4 Predicted abundance of $G$. alba $\mathbf{a}, \mathbf{b}$ and $G$. vitellina $\mathbf{c}$ as a function of dry season soil moisture (volumetric water content, $\mathrm{m}^{3} \mathrm{~m}^{-3}$ ) based on a present versus extinct sites or b and c present versus adjacent sites. Circles are actual observations, solid lines are the model predictions, and grey areas denote $95 \%$ confidence intervals. Predicted abundance and confidence intervals were generated with a GLM without random effects, holding all other significant variables constant on their means

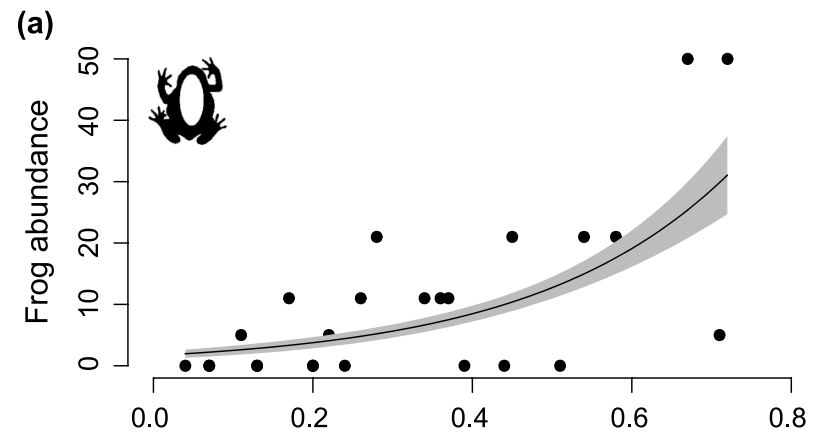

(b)

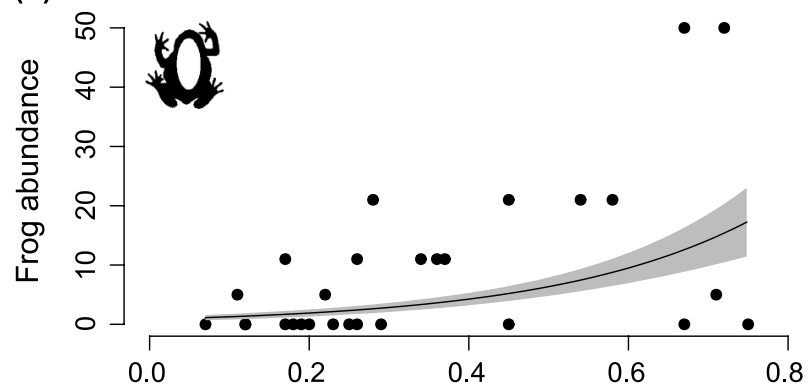

(c)

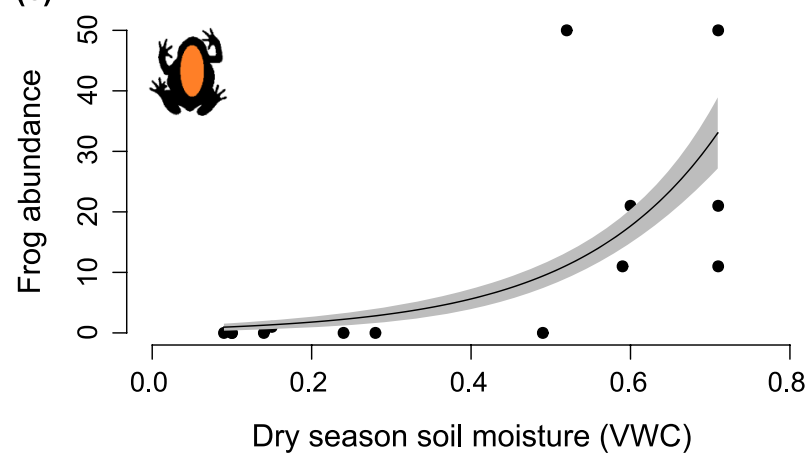

vitellina, where there was no overlap between present and adjacent sites. The presence of both species was positively related to soil moisture at the ends of the wet (December) and dry (April) seasons, and to moss cover, and was negatively associated with bare ground, temperature maximum and temperature range during summer (February). This demonstrates that both species require relatively cooler, wetter, and mossier sites, with more ground cover.

Dry season soil moisture measured in April was the principal habitat factor determining $G$. alba and G. vitellina occurrence and abundance at sites. This time is towards the end of a drier-hotter period (Fig. 2) and when the drainage areas where frogs occur are likely at their driest. Soil moisture varied considerably during this time, even across small distances, with sites where frogs were present having significantly higher soil moisture than adjacent patches in the same riparian habitat $50 \mathrm{~m}$ away. As the surrounding open woodland habitat is drier (E. Hoffmann, unpublished data), both species appear to be utilising patches along 


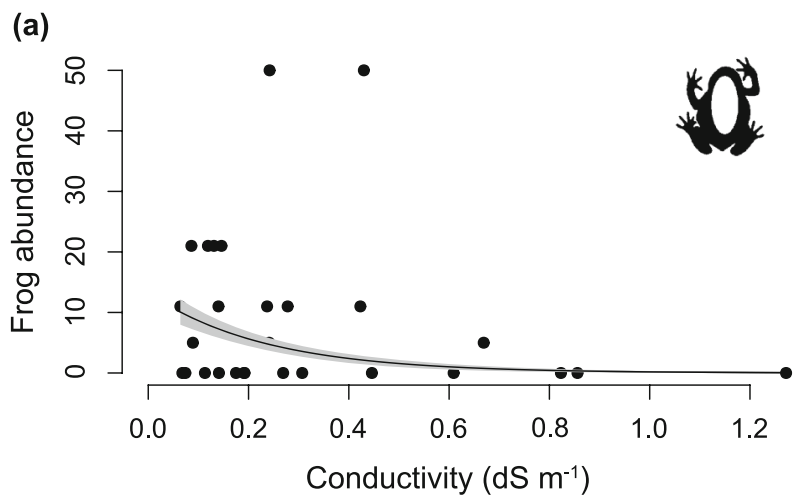

(b)

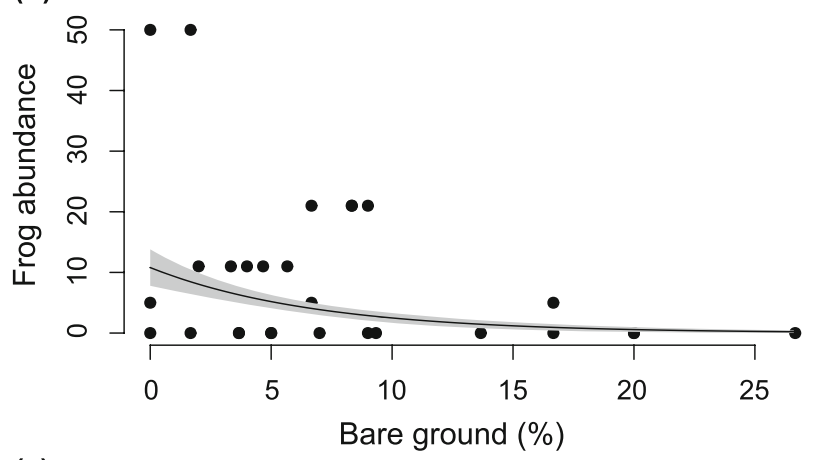

(c)

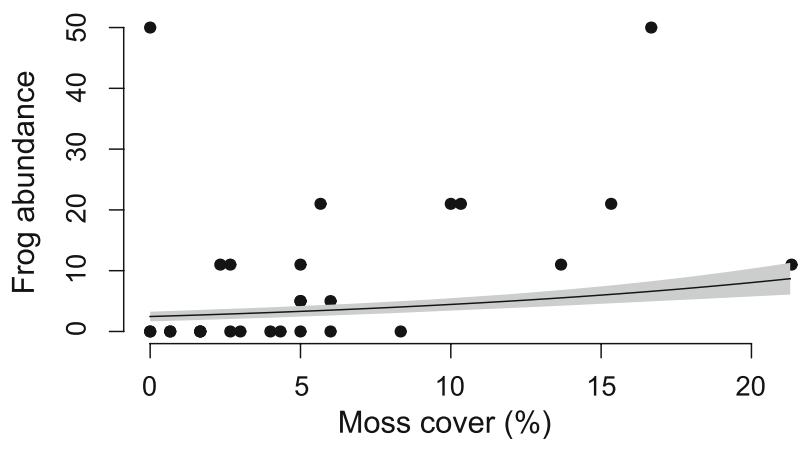

Fig. 5 Predicted abundance of Geocrinia alba as a function of a soil conductivity, $\mathbf{b}$ bare ground and $\mathbf{c}$ moss cover, based on present versus adjacent sites. Solid lines are the model predictions, grey areas denote $95 \%$ confidence intervals, and circles are actual observations. Predicted abundance and confidence intervals were generated with a GLM without random effects, holding all other significant variables constant on their means

drainage lines that retain the highest moisture in the dry season. Soil water availability in summer-autumn may therefore be the defining factor that determines the patchy and restricted distributions for both species. Soil temperature (both maximum and range) was significantly correlated with soil moisture, and therefore drier areas were also warmer. The summer dry season may therefore be a critical period for G. alba and G. vitellina and potentially more important in determining population persistence than winter-spring 
Fig. 6 Estimates of the number of calling males at Geocrinia translocation sites and predicted abundance ( \pm standard error) based on models using dry season soil moisture as the predictor variable

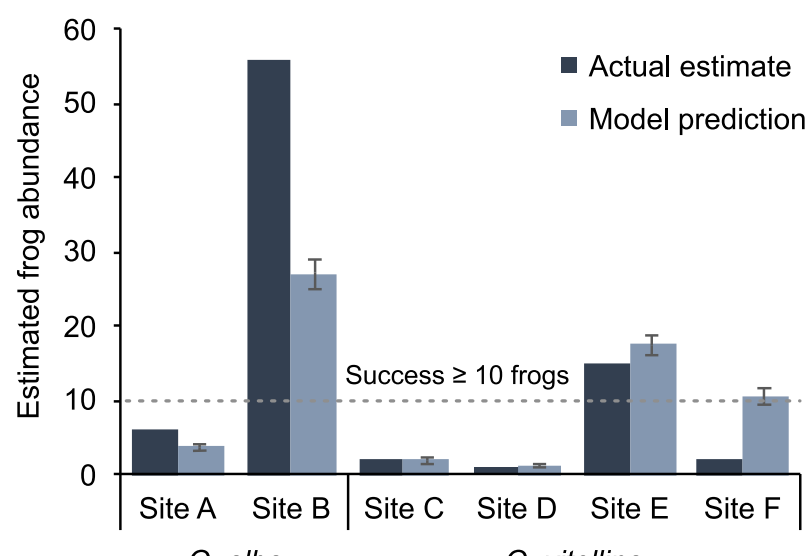

G. alba
G. vitellina

breeding conditions. Currently, nearly all research conducted has focused on the G. alba and G. vitellina breeding period in spring (Driscoll 1996; Pauli 1999; Conroy 2001; Mitchell 2001), and little is known about their behaviour and habitat in the drier and warmer summer-autumn period.

Lower frog abundance or absence at drier sites could be due to desiccating conditions experienced by frogs and their egg masses. The physiological constraints of moisture on amphibians is well known (Shoemaker et al. 1992), and drier conditions at the end of the breeding period could lead to reduced or failed recruitment. Both species breed over a prolonged period following winter rains, laying eggs in moist depressions in the soil adjacent to winter streams. Egg laying and development can continue into December and January, several months into the drier period (Driscoll 1996; Conroy 2001) (Fig. 2). Incubation in drier conditions causes terrestrial frog eggs to lose water from their jelly capsules and embryos have higher rates of deformations and mortality (Bradford and Seymour 1988; Mitchell 2002b; Andrewartha et al. 2008). If soils remain saturated throughout embryonic and larval development, newly metamorphosed frogs emerge just prior to the warmest and driest time of year (around November-January, Fig. 2) and are vulnerable to desiccation due to their very small size $(\sim 0.03 \mathrm{~g}$ at metamorphosis $)$ and large surface area to volume ratio. Juvenile amphibians consequently lose more moisture and experience lower survival than adults in hotter and drier landscapes (Cayuela et al. 2016). The juvenile stage is not only the most vulnerable, but also prolonged, lasting at least two years (Driscoll 1999). Both Geocrina species rely on high juvenile survival due to low fecundity (with an average of 11 eggs per clutch) and because most adults only breed once (Driscoll 1999; Conroy 2001). Population viability modelling of G. alba and $G$. vitellina has indicated that a reduction in juvenile survival would have the biggest impact on population trends compared with other life stages (Conroy and Brook 2003). Therefore, we infer that frogs are at risk of desiccation during the dry phase, and juveniles are likely the most vulnerable life stage.

Local extinctions throughout the range of $G$. alba also appear to be driven by habitat differences, with extinct sites being significantly drier in summer and less mossy than present and adjacent sites. Hydrological change had been suggested as one of the main threats to G. alba (e.g. Driscoll 1996; Pauli 1999; Conroy 2001), but until this study, there were no quantitative data to evaluate the importance of site hydrology, specifically soil moisture, as a factor in G. alba declines. Considerable land clearance and land-use change 
has occurred within $G$. alba's range. It is estimated that $70 \%$ of potentially suitable habitat has been removed and most of the clearance has occurred relatively recently, between 1960 and 1980 (Pauli 1999; Page et al. 2018). Clearing of native vegetation may increase stream flows and groundwater levels, at least in the short term (Bari et al. 1996), but these increases may have been offset by extensive land-use change following vegetation clearance, such as expansions of orchards, forestry plantations, barriers to flow (e.g. roads) and installation of dams, and could be reducing flows to G. alba catchments (Department of Parks and Wildlife 2015). Despite the clear attribution of local extinctions of some populations to land clearance and adjacent land use change, most of the extinct G. alba sites sampled in this study were within stands of native vegetation and conservation estate (with the upstream catchment entirely within reserve or native vegetation block) and so should be less impacted by land clearance and hydrological alterations, such as dams. Consequently, the pattern of extinctions at drier sites may also reflect hydro-climatological changes that are occurring in the region on a broader scale.

There is mounting evidence of substantial climatic and hydrological change occurring in the region. South-west Western Australia has experienced a 15-20\% decline in rainfall and a consequent $35-50 \%$ reduction in streamflow since the 1970s, with the biggest rainfall changes occurring at the start of the wetter winter period in May and June (Petrone et al. 2010; McFarlane et al. 2020). Reduced rainfall in winter is increasing the length of the "noflow' period in rivers of the region, with surface flows in ephemeral creek lines commencing later and ending earlier (e.g. Smettem et al. 2013). Furthermore, riparian habitats may also be impacted by decreasing groundwater levels in the region (McFarlane et al. 2020). Streamflow is dominated by winter rainfall, but some catchments in Geocrinia habitats overlie sedimentary aquifers (e.g. Upper Chapman Brook) and may receive groundwater inputs during summer (Department of Water 2015). If sites rely on groundwater seepage to retain moisture over summer and autumn, lower groundwater levels could be resulting in drier summer conditions. As we showed that drier soils had higher maximum temperatures and greater temperature ranges, drier sites are also likely to be more impacted by the warmer air temperatures that have been observed and predicted to increase in the region (Charles et al. 2010). Therefore, regional changes in climate and hydrology are likely to be resulting in drainage habitats receiving less surface water and groundwater inputs, and consequently, experiencing more extreme temperatures and drying. The changes being experienced in headwater systems may be amplified as the relationship between rainfall decline and streamflow can be highly non-linear (e.g. $1 \%$ rainfall decline $\geq 3 \%$ runoff decline; McFarlane et al. 2020) and through a disconnection of groundwater-surface water connectivity due to declining groundwater levels (Petrone et al. 2010).

If drying of some G. alba habitats is due to regional changes in climate or hydrology, why is G. vitellina not declining? Geocrinia vitellina occurs in sites that are less sandy than G. alba sites and thereby retain higher soil moisture. Geocrinia vitellina also occurs on drainage lines that may receive groundwater inputs from the deeper Yarragadee and Leederville aquifers, buffering these areas from drying over summer (CSIRO 2009). Therefore, G. vitellina habitats may be less vulnerable to hydrological changes. However, G. vitellina also appears to be highly restricted to wetter patches within riparian drainage habitats in the dry period, as adjacent areas where frogs didn't occur were significantly drier. They also share the same specialised breeding requirements, limited dispersal ability, and very small area of occurrence as G. alba. Therefore, whilst only G. alba has shown extreme declines, both species are threatened by habitat and range contraction associated with climatic and hydrological changes occurring in the region. For example, groundwater 
tables in the Blackwood plateau underlying $G$. vitellina habitat are currently declining at $\sim 1.2 \mathrm{~m} /$ year and are predicted to drop $10 \mathrm{~m}$ in some areas by 2030 (CSIRO 2009). More recent population monitoring has also indicated that some G. vitellina populations are showing signs of decline (K. Williams, unpublished observation).

In addition to soil moisture levels, habitat structure and other soil parameters were also important in determining G. alba abundance. Most notably, compared with sites where $G$. alba were present, extinct sites had less moss cover. Adjacent areas were also associated with lower moss cover, as well as more bare ground and higher soil conductivity. More moss and ground cover at sites where G. alba are present would provide frogs with more habitat for nest construction, as well as greater protection from desiccation (Glime and Boelema 2017). The electrical conductivity levels in the drainage lines were generally low $\left(<1 \mathrm{dS} \mathrm{m}{ }^{-1}\right)$ but indicated that $G$. alba prefer areas with lower soil conductivity. Conductivity is an indicator of salinity, which can cause osmotic stress (Smith et al. 2007) and can decrease growth and survival of amphibians at higher concentrations (Chinathamby et al. 2006; Kearney et al. 2012).

\section{Management implications}

Here we have demonstrated that gaining a detailed understanding of species habitat-associations can provide vital information for conservation management. Studies of habitat requirements typically compare occupied and unoccupied habitats, but we additionally evaluated the outcomes of translocations in the context of habitat variability. This approach highlighted that fine-scale habitat attributes are likely to be a key driver of translocation success, as we were able to hindcast translocation outcomes with high accuracy using only dry season soil moisture as the predictor variable. Therefore, using dry season soil moisture to select translocation sites should increase the likelihood of success of new translocations. We suggest that sites should have soil moisture contents of at least $40 \%$ during the drier period to sustain a population of $>10$ calling males. Very few frogs were recorded at sites where soil moisture content was below 20\%, indicating that sites below this moisture threshold are unlikely to support G. alba or G. vitellina populations long-term. These recommendations are tentative in recognition that our predictions are based on one year of data, and the variability and extremes the sites experience throughout the year is unknown. Further, soil moisture per se has limited biological relevance to amphibians, as soil water potential drives water availability and varies substantially with soil type (Shoemaker et al. 1992). However, as soil moisture content can be measured more simply than water potential, it is a practical method to rapidly detect relatively wetter and drier areas.

More broadly, we highlight that conservation areas may not provide a buffer against wider regional threats, such as drying brought about by climate change. This corroborates our related study showing that physiological tolerance limits of $G$ alba. and $G$. vitellina are being breached in atypically warm periods (Hoffmann et al. in review), and other studies that have recorded impacts of drought on amphibians within conservation estates in other regions of Australia (Scheele et al. 2012) and the world (McMenamin et al. 2008; Cayuela et al. 2016). Mitigating broad scale impacts of changing hydrology and climate (e.g. those that are occurring across entire species ranges) including in protected areas, is an imposing management challenge. Some suggested strategies include providing microclimate refugia through watering actions, such as sprinkler systems to wet soils or artificial filling of wetlands (see Shoo et al. 2011 for a summary), which may help alleviate pressures at key sites in the short term. Groundwater levels are heavily linked to rainfall but also vegetation 
(CSIRO 2009). Reversing groundwater declines, as well as increases in streamflow, could potentially be achieved by a reduction in upland vegetation via thinning (Jones et al. 2018) and has been trialled in Jarrah forests in Western Australia (e.g. Stoneman, 1993), but requires consideration of other biodiversity values. Another conservation approach when habitats become marginal due to climate change is assisted colonisation, where species are moved to areas outside of their indigenous range that will become suitable in the near future (Mitchell et al. 2013; Gallagher et al. 2015). Our findings suggest that the conditions that led to the loss of $G$. alba populations have not alleviated, and that sites where the species became extinct are not suitable for recolonisation, making assisted colonisation worthy of consideration. A priority should be to detect areas that currently stay moist or retain shallow surface water year-round and to evaluate their resilience to future hydrological change, as these areas may provide important refugia for the species into the future.

Our findings also have implications for other taxa and locations. Local extinctions of $G$. alba are potentially among the first signs of impacts of changes to the hydrology of drainage areas and headwaters on regional biodiversity, and the impacts on other waterdependent fauna and flora that occur in these systems is unknown (e.g. threatened Engaewa spp.- - endemic burrowing crayfish). We also detected critical habitat differences on an extremely fine-scale, just tens of meters along drainage lines. These distances are much finer in scale than the focus of much climate and species distribution modelling, emphasising the need to consider modelling habitat variables at the scale most relevant to that species. Many mid-latitude areas of the world are experiencing a drying and warming trend, and our study highlights the vulnerability of sedentary and specialised water-sensitive species in an era of rapid environmental change.

Acknowledgements We thank the Western Australian Department of Biodiversity, Conservation and Attractions, in particular Christine Taylor, for assistance with project planning, logistics and site access. This research was completed under a DBCA Regulation 4 Permit and University of Western Australia Animal Ethics Permit RA/3/100/1554. This research was supported by the Australian Government's National Environmental Science Program through the Threatened Species Recovery Hub, the Forrest Research Foundation, the Mohamed bin Zayed Species Conservation Fund, the Holsworth Wildlife Research Endowment and The Ecological Society of Australia. We are grateful to landholders for property access, and to Irene Wegener and Bruno Buzatto for fieldwork assistance. The study was enhanced by discussions with the Geocrinia Recovery Team, Dale Roberts and Natasha Pauli, and statistical advice from Bruno Buzatto.

Authors contributions EPH-Conceptualization, Methodology, Formal Analysis, Writing-Original Draft, Writing-Review \& Editing, Visualization, Funding acquisition. KW-Conceptualization, Resources, Writing-Review \& Editing. MRH-Writing-Review \& Editing, Supervision. NJM-Conceptualization, Supervision, Writing-Review \& Editing, Funding acquisition.

Funding This research was supported by the Australian Government's National Environmental Science Program through the Threatened Species Recovery Hub, the Forrest Research Foundation, the Mohamed bin Zayed Species Conservation Fund, the Holsworth Wildlife Research Endowment and The Ecological Society of Australia.

Data availability Due to the sensitive nature of the species locations the datasets from the current study are not publicly available but are available from the corresponding author on reasonable request.

Code availability Not applicable.

\section{Compliance with ethical standards}

Conflict of interest The authors declare that they have no conflict of interest. 
Ethical approval This research was completed under a DBCA Regulation 4 Permit and University of Western Australia Animal Ethics Approval RA/3/100/1554.

Consent to participate Not applicable.

Consent for publication Not applicable.

Open Access This article is licensed under a Creative Commons Attribution 4.0 International License, which permits use, sharing, adaptation, distribution and reproduction in any medium or format, as long as you give appropriate credit to the original author(s) and the source, provide a link to the Creative Commons licence, and indicate if changes were made. The images or other third party material in this article are included in the article's Creative Commons licence, unless indicated otherwise in a credit line to the material. If material is not included in the article's Creative Commons licence and your intended use is not permitted by statutory regulation or exceeds the permitted use, you will need to obtain permission directly from the copyright holder. To view a copy of this licence, visit http://creativecommons.org/licenses/by/4.0/.

\section{References}

Andrewartha SJ, Mitchell NJ, Frappell PB (2008) Phenotypic differences in terrestrial frog embryos: effect of water potential and phase. J Exp Biol 211:3800-3807

Anstis M (2010) A comparative study of divergent embryonic and larval development in the Australian frog genus Geocrinia (Anura: Myobatrachidae). Rec West Aust Museum 25:399-440

Bari MA, Smith N, Ruprecht JK, Boyd BW (1996) Changes in streamflow components following logging and regeneration in the Southern Forest of Western Australia. Hydrol Process 10:447-461

Bartoń K (2019) MuMIn: Multi-Model Inference. R package version 1.43.15

Bates D, Maechler M, Bolker B, Walker S (2015) Fitting linear lixed-effects models using lme4. J Stat Softw 67:1-48

Bennett VA, Doerr VAJ, Doerr ED et al (2013) Causes of reintroduction failure of the brown treecreeper: Implications for ecosystem restoration. Austral Ecol 38:700-712. https://doi.org/10.1111/aec.12017

Blaustein AR, Walls SC, Bancroft BA et al (2010) Direct and indirect effects of climate change on amphibian populations. Diversity 2:281-313. https://doi.org/10.3390/d2020281

Booth GD, Niccolucci MJ, Schuster EG (1994) Identifying proxy sets in multiple linear regression: an aid to better coefficient interpretation. Research paper INT-470. Ogden, Utah

Bradford DF, Seymour RS (1988) Influence of water potential on growth and survival of the embryo, and gas conductance of the egg, in a terrestrial breeding frog, Pseudophryne bibroni. Physiol Zool 61:470-474

Bureau of Meteorology (2019) Average annual, seasonal and monthly rainfall. https://www.bom.gov.au/jsp/ ncc/climate_averages/rainfall/index.jsp. Accessed 20 Dec 2019

Burnham KP, Anderson DR (2002) A practical information-theoretic approach. In: Burnham KP, Anderson DR (eds) Model selection and multimodel inference, 2nd edn. Springer, New York

Caughley G (1994) Directions in conservation biology. J Anim Ecol 63:215-244. https://doi.org/10.2307/ 5542

Cayuela H, Arsovski D, Bonnaire E et al (2016) The impact of severe drought on survival, fecundity, and population persistence in an endangered amphibian. Ecosphere 7:1-12. https://doi.org/10.1002/ecs2. 1246

Charles S, Silberstein R, Teng J, et al (2010) Climate analyses for South-West Western Australia: A report to the Australian Government from the CSIRO South-West Western Australia Sustainable Yields Project. 1-83

Chinathamby K, Reina RD, Bailey PCE, Lees BK (2006) Effects of salinity on the survival, growth and development of tadpoles of the brown tree frog, Litoria ewingii. Aust J Zool 54:97-105. https://doi.org/ $10.1071 / \mathrm{ZO} 06006$

Conroy SDS (2001) Population biology and reproductive ecology of Geocrinia alba and G. vitellina, two threatened frogs from southwestern Australia. PhD Thesis, University of Western Australia: Perth, Australia.

Conroy SDS, Brook BW (2003) Demographic sensitivity and persistence of the threatened white- and orange-bellied frogs of Western Australia. Popul Ecol 45:105-114

CSIRO (2009) Groundwater yields in south-west Western Australia. A Report to the Australian Government from the CSIRO South-West Western Australia Sustainable Yields Project 
Department of Parks and Wildlife (2015) White-bellied and Orange-bellied Frogs (Geocrinia alba and Geocrinia vitellina) Recovery Plan. Perth, Western Australia

Department of Water (2015) River health assessment in the lower catchment of the Blackwood River. Water Science Technical series, Report no, p 68

Dodd CK (2010) Amphibian ecology and conservation: a handbook of techniques. Oxford University Press, New York

Driscoll DA (1997) Mobility and metapopulation structure of Geocrinia alba and Geocrinia vitellina, two endangered frog species from southwestern Australia. Aust J Ecol 22:185-195. https://doi.org/10.1111/ j.1442-9993.1997.tb00658.x

Driscoll DA (1998a) Genetic structure, metapopulation processes and evolution influence the conservation strategies for two endangered frog species. Biol Conserv 83:43-54. https://doi.org/10.1016/S00063207(97)00045-1

Driscoll DA (1998b) Counts of calling males as estimates of population size in the endangered frogs Geocrinia alba and G. vitellina. J Herpetol 32:475-481. https://doi.org/10.2307/1565200

Driscoll DA (1996) Understanding the metapopulation structure of frogs in the Geocrinia rosea group through population genetics and population biology: Implications for conservation and evolution. $\mathrm{PhD}$ Thesis, University of Western Australia: Perth, Australia.

Driscoll DA (1999) Skeletochronological assessment of age structure and population stability for two threatened frog species. Aust J Ecol 24:182-189. https://doi.org/10.1046/j.1442-9993.1999.241961.x

Fox J, Weisberg S (2019) An R companion to applied regression, 3rd edn. Sage Publications, California

Gallagher RV, Makinson RO, Hogbin PM, Hancock N (2015) Assisted colonization as a climate change adaptation tool. Austral Ecol 40:12-20

Germano JM, Bishop PJ (2009) Suitability of amphibians and reptiles for translocation. Conserv Biol 23:7-15. https://doi.org/10.1111/j.1523-1739.2008.01123.x

Glime JM, Boelema WJ (2017) Amphibians: Anuran adaptations. In: Glime JM (ed) Bryophyte Ecology, Bryological Interaction, vol 2. Ebook sponsored by Michigan Technological University and the International Association of Bryologists. Last updated 21 April 2017.

Grueber CE, Nakagawa S, Laws RJ, Jamieson IG (2011) Multimodel inference in ecology and evolution: challenges and solutions. J Evol Biol 24:699-711. https://doi.org/10.1111/j.1420-9101.2010.02210.x

Harrison XA, Donaldson L, Correa-Cano ME et al (2018) A brief introduction to mixed effects modelling and multi-model inference in ecology. PeerJ 6:e4794

Hartig F (2020) DHARMa: Residual diagnostics for hierarchical (multi-level/mixed) regression models. R package version 0.2.7.

Hillman SS, Withers PC, Drewes RC, Hillyard SD (2009) Ecological and environmental physiology of amphibians. Oxford University Press, New York

Jones CN, McLaughlin DL, Henson K et al (2018) From salamanders to greenhouse gases: does upland management affect wetland functions? Front Ecol Environ 16:14-19. https://doi.org/10.1002/fee.1744

Kearney BD, Byrne PG, Reina RD (2012) Larval tolerance to salinity in three species of australian anuran: an indication of saline specialisation in Litoria aurea. PLoS ONE 7:1-6. https://doi.org/10.1371/ journal.pone. 0043427

Kuhn M (2018) The caret package. R package version 6.0-81.

Li Y, Cohen JM, Rohr JR (2013) Review and synthesis of the effects of climate change on amphibians. Integr Zool 8:145-161. https://doi.org/10.1111/1749-4877.12001

McCulloch N, Norris K (2001) Diagnosing the cause of population changes: localized habitat change and the decline of the endangered St Helena wirebird. J Appl Ecol 38:771-783. https://doi.org/10.1046/j. 0021-8901.2001.00630.x

McFarlane D, George R, Ruprecht J et al (2020) Runoff and groundwater responses to climate change in South West Australia. J R Soc West Aust 103:9-27

McMenamin SK, Hadly EA, Wright CK (2008) Climatic change and wetland desiccation cause amphibian decline in Yellowstone National Park. Proc Natl Acad Sci 105:16988-16993. https://doi.org/10.1073/ pnas.0809090105

Mitchell NJ (2001) The energetics of endotrophic development in the frog Geocrinia vitellina (Anura: Myobatrachinae). Physiol Biochem Zool 74:832-842

Mitchell NJ (2002a) Nest-site selection in a terrestrially breeding frog with protracted development. Aust J Zool 50:225-236

Mitchell NJ (2002b) Low tolerance of embryonic desiccation in the terrestrial nesting frog Bryobatrachus nimbus (Anura: Myobatrachinae). Copeia 2:364-373

Mitchell NJ, Hipsey MR, Arnall S et al (2013) Linking eco-energetics and eco-hydrology to select sites for the assisted colonization of Australia's rarest reptile. Biology 2:1-25. https://doi.org/10.3390/ biology 2010001 
Morris K, Page M, Kay R, et al (2015) Forty years of fauna translocations in lessons learned. In: Armstrong D, Hayward M, Moro D, Seddon P (eds) Advances in reintroduction biology of fauna. CSIRO Publishing, Victoria. pp 217-235

Oksanen J, Blanchet FG, Friendly M, et al (2019) vegan: Community Ecology Package. R package version $2.5-4$.

Page M, Bradfield K, Williams K (2018) Underbelly: the tale of the threatened white-bellied frog. In: Garnett S, Latch P, Lindenmayer D, Woinarski J (eds) A Book of Hope. CSIRO Publishing, Recovering Australian Threatened Species, pp 207-216

Pauli N (1999) Environmental factors and extinction in the White-Bellied Frog, Geocrinia alba. Unpublished Honours Thesis. The University of Western Australia, Perth.

Pereira HM, Navarro LM, Martins IS (2012) Global biodiversity change: the bad, the good, and the unknown. Annu Rev Environ Resour 37:25-50. https://doi.org/10.1146/annurev-environ-042911093511

Petrone KC, Hughes JD, Van Niel TG, Silberstein RP (2010) Streamflow decline in southwestern Australia, 1950-2008. Geophys Res Lett 37:1-7. https://doi.org/10.1029/2010GL043102

R Core Team (2019) R: A language and environment for statistical computing. R Foundation for Statistical Computing, Vienna, Austria

Read K, Keogh JS, Scott IAW et al (2001) Molecular phylogeny of the Australian frog genera Crinia, Geocrinia, and allied taxa (Anura: Myobatrachidae). Mol Phylogenet Evol 21:294-308

Richards SA, Whittingham MJ, Stephens PA (2011) Model selection and model averaging in behavioural ecology: The utility of the IT-AIC framework. Behav Ecol Sociobiol 65:77-89. https://doi.org/10. 1007/s00265-010-1035-8

Rolland J, Silvestro D, Schluter D et al (2018) The impact of endothermy on the climatic niche evolution and the distribution of vertebrate diversity. Nat Ecol Evol 2:459-464. https://doi.org/10.1038/s41559017-0451-9

Scheele BC, Gillespie GR (2018) The extent and adequacy of monitoring for Australian threatened frog species. In: Legge S, Lindenmayer DB, Robinson NM, et al (eds) CSIRO Publishing, Melbourne, pp 57-68

Scheele BC, Driscoll DA, Fischer J, Hunter DA (2012) Decline of an endangered amphibian during an extreme climatic event. Ecosphere 3:101. https://doi.org/10.1890/es12-00108.1

Shoemaker VH, Hillman SS, Hillyard SD et al (1992) Exchange of water, ions and respiratory gases in terrestrial amphibians. In: Feder ME, Burggren WW (eds) Environmental physiology of the amphibians. University of Chicago Press, Chicago, pp 125-150

Shoo LP, Olson DH, McMenamin SK et al (2011) Engineering a future for amphibians under climate change. J Appl Ecol 48:487-492. https://doi.org/10.1111/j.1365-2664.2010.01942.x

Smettem KRJ, Waring RH, Callow JN et al (2013) Satellite-derived estimates of forest leaf area index in southwest Western Australia are not tightly coupled to interannual variations in rainfall: Implications for groundwater decline in a drying climate. Glob Chang Biol 19:2401-2412. https://doi.org/10.1111/ gcb. 12223

Smith MJ, Schreiber ESG, Scroggie MP et al (2007) Associations between anuran tadpoles and salinity in a landscape mosaic of wetlands impacted by secondary salinisation. Freshw Biol 52:75-84. https://doi. org/10.1111/j.1365-2427.2006.01672.x

Stoneman GL (1993) Hydrological response to thinning a small jarrah (Eucalyptus marginata) forest catchment. J Hydrol 150:393-407. https://doi.org/10.1016/0022-1694(93)90118-S

Stuart SN, Chanson JS, Cox NA et al (2004) Status and trends of amphibian declines and extinctions worldwide. Science 306:1783-1786. https://doi.org/10.1126/science.1103538

Threatened Species Scientific Committee (TSSC) (2019) Conservation Advice Geocrinia alba (Whitebellied Frog). Canberra: Department of the Environment and Energy. https://www.environment.gov. au/biodiversity/threatened/species/pubs/26181-conservation-advice-04072019. 13 April 2020

Walls SC, Barichivich WJ, Brown ME (2013) Drought, deluge and declines: the impact of precipitation extremes on amphibians in a changing climate. Biology 2:399-418. https://doi.org/10.3390/ biology2010399

Wardell-Johnson G, Roberts JD (1993) Biogeographic barriers in a subdued landscape: The distribution of the Geocrinia rosea (Anura: Myobatrachidae) complex in south-western Australia. J Biogeogr 20:95-108. https://doi.org/10.2307/2845743

Wyman RL (1988) Soil acidity and moisture and the distribution of amphibians in five forests of southcentral New York. Copeia 2:394-399. https://doi.org/10.2307/1445879

Publisher's Note Springer Nature remains neutral with regard to jurisdictional claims in published maps and institutional affiliations. 


\section{Affiliations}

\section{Emily P. Hoffmann ${ }^{1}$ (D) Kim Williams $^{2} \cdot$ Matthew R. Hipsey $^{3}$ (D)} Nicola J. Mitchell ${ }^{1}$

1 School of Biological Sciences, The University of Western Australia, Crawley, WA 6009, Australia

2 Department of Biodiversity Conservation and Attractions, Parks and Wildlife Service, Bunbury, WA, Australia

3 School of Agriculture and Environment, The University of Western Australia, Crawley, WA 6009, Australia 